\title{
Konaklama İşletmelerinde Çalışma Sermayesi Yönetiminin Karlılık Performansına Etkisi: Borsa İstanbul'da (Bist) Bir Uygulama
}

\section{The Effects of Working Capital Management on Profitability Performance in Accommodation Establishments: An Application on Borsa Istanbul (Bist)}

Yrd. Doç. Dr. Yeşim HELHEL

Akdeniz Üniversitesi

Turizm Fakültesi

E-posta: yhelhel@akdeniz.edu.tr Orcid Id: 0000-0002-1293-6450
Arş. Gör. Sezer KARASAKAL

Antalya Bilim Üniversitesi

Turizm Fakültesi

E-posta:sezer.karasakal@antalya.edu.tr

Orcid Id: 0000-0002-4713-2735

Öz

Bu çalışmanın amacı, konaklama sektöründe faaliyet gösteren Borsa İstanbul'a kayıtlı (BIST) işletmelerin çalışma sermayesi yönetiminin karlıık performansına etkisini incelemektir. 5 adet konsolide bilançoya tabi olmayan konaklama işletmesine ait 20052015 dönemine ilişkin veriler kullanılmıştır. Karlılık performansı değişkenleri aktif karlılık ve öz sermaye karlılık oranları olarak belirlenmiştir. Toplam borç oranı (kaldıraç) ve net işletme sermayesi oranının işletmelerin her iki karlılık performans ölçütünü negatif yönde etkilediği, aktif devir hızı ve alacak devir hızının aktif karılığı pozitif yönde etkilediği görülmüştür. Diğer değişkenlerin ise karlılık üzerinde bir etkisinin olmadığı tespit edilmiştir. Analiz sonuçları bir bütün olarak değerlendirildiğinde, konaklama sektöründe çalışma sermayesi değişkenlerinin karlılık performansına etkisi birkaç değişkenle sınırlıdır.

Anahtar Kelimeler: Çalışma sermayesi yönetimi, Karlılık performansı, Konaklama sektörü, Panel veri analizi

\begin{abstract}
The aim of this study is to analyze the effects of working capitalmanagement on profitability performance of listed accommodation establishments in Borsa Istanbul (BIST). Data belonging from 5 accommodation establishments that are not subject to consolidated financial statements are used for 2005-2015 time intervals. Return on asset $(R O A)$ and return on equity (ROE) are determined as profitability performance variables. It has been observed that both of the profitability performance of establishments is affected negatively by total liability (leverage) and net working capital ratio. Asset and trade receivables turnover ratios affect return on asset positively. Other working capital variables are explored to have no effect on profitability. Overall analysis concludes that the effects of working capital on profitability performance are limitedin accommodation sector.
\end{abstract}

Keywords: Accommodation sector, Panel data analysis, Profitability performance, Working capital management. 


\section{Giriş}

Turizme katılan bireylerin sayısının her yıl artması ve buna bağlı olarak turizm sektörüne yapılan özel ve kamu yatıımlarının artış göstermesi, büyük bütçeli işletmelerin ortaya çıkmasını hızlandırmıştır. Son yıllarda patron otellerinin ve küçük ölçekli aile işletmelerinin yerini büyük ölçekli kurumsal işletmeler almaya başlamıştır. İstihdam sayısındaki artış, geniş pazarlarda faaliyet gösterme, bilgi ve iletişim teknolojisindeki hızlı gelişmeler ve büyüyen ekonomik hacim turizm işletmelerinin daha profesyonel bir yönetim intiyacını da beraberinde getirmiştir. Öte yandan, turizm sektörü ve özelde konaklama işletmelerinin ürünlerinin stoklanamaz olması, sabit sermaye yatırımlarının yüksek maliyetli olması, talep dalgalanmalarına karşı aşırı hassasiyetin olması, operasyonel faaliyetlerin turizm sektörünün doğası gereği karmaşık ve maliyetli olması gibi nedenler, rekabetin giderek artığı konaklama işletmelerinde çalışma sermayesi yönetiminin önem kazanmasına neden olmuştur.

Çalışma sermayesi işletmelerin çalışma dönemleri içinde paraya çevrilebilecek veya en azından bir kısmı yenilenecek varlıklarını tanımlamak için kullanılan bir finansal yönetim ifadesidir (Büker ve diğ. 2009:205). Gerçekleşecek tutar ve gerçekleşme tarihleri gibi nakit giriş ve çıkışları arasında görülen uyumsuzluklar ile tutarlarının önceden kesin olarak bilinememesi çalışma sermayesini doğuran ana nedenlerdir (Sayılgan 2010:161). Gerçek iş hayatı koşullarında "tam belirlilik" durumu söz konusu değildir. İşletmelerin tam kapasite çalışmaları, faaliyetlerine kesintisiz devam edebilmeleri, kısa vadeli borçlarını ve faizlerini ödeyebilmeleri, karşılaşabileceği riskleri en aza indirebilme ve faaliyetlerini karlı bir şekilde devam ettirebilmeleri için çalışma sermayesine yapılan yatırımlar önem arz etmektedir.

Satışları mevsimsel dalgalanma gösteren konaklama işletmelerinde işletme sermayesi gereksinimi de dalgalanma göstermektedir. Dalgalanma ve değişiklikler belirsizliği ve dolayısıyla riski artırmaktadır. Etkin çalışma sermayesi yönetimi, firmaların aldığı riskler ve karlılıkları arasındaki uygun bir denge sağlayarak kısa vadeli yükümlülüklerini yerine getirmesini ve bu yerine getirme sürecinde karşılaşabileceği risklerin giderilmesini, dönen varlıklarda yer alan kalemlere aşırı yatııı yapılmasını ortadan kaldırmak için dönen varlıklar ve kısa vadeli yükümlülüklerin planlanmasını ve nihai olarak denetlenmesini kapsamaktadır (Toraman ve Sönmez 2015:16). Etkin yönetim, çalışma sermayesi yatıımlarını azaltma ve kısa vadeli borçlarını artırma yönünde bir politika belirlemiş ise finansal risk maliyetine katlanmadığı müddetçe karııı̆ı artırmakta ve finansal sıkıntı ve iflas ile karşılaşma riskini azaltmaktadır (Coşkun ve Kök 2011: 76).

Finans yazını irdelendiğinde; çalışma sermayesi yönetimi ile finansal performans göstergelerinden en önemlisi olarak kabul edilen karlılık arasında ilişkiyi test eden birçok çalışmaya rastlanılmaktadır. Çalışmaların büyük bir kısmında çalışma sermayesi değişkeni olarak "nakit dönüşüm süresi" kullanılmıştır. Shin ve Soenen (1998) 58.985 adet firmanın 1975-1994 yılları arasındaki verilerini kullanarak nakit dönüşüm süresi ile karlılık arasında negatif bir ilişki olduğunu göstermiştir. Wang (2002) Japonya ve Tayland'daki firmaların nakit dönüşüm süresi ile aktif karlılık ve özsermaye karlılık oranı arasında negatif ilişki olduğu ve bu ilişkinin sektörlere göre duyarlılık hassasiyetinin farklı olduğunu tespit etmiştir. Türkiye'de yapılan bir çalışmada ise nakit dönüşüm süresinin aktif karlılık üzerinde istatistiki olarak anlamlı bir etkisinin olmadığı sonucuna ulaşılmıştır (Saldanlı, 2012).

Çalışma sermayesinin diğer değişkenlerini dikkate alarak karlılık performansına etkisini inceleyen çalışmaların sayısı da oldukça fazladır. Deelof (2003) 1.009 adet 
Belçikalı finansal olmayan büyük işletme üzerinde yaptığı araştırmada ortalama ticari alacak, stokta tutma ve ticari borçları ödeme süresinin faaliyet karlılığını negatif yönde etkilediğini bulmuştur. Ademola (2014) Nijerya borsasına kayıtlı yiyecek içecek sektöründe faaliyet gösteren 120 adet işletmenin 2002-2011 verilerini kullanarak çalışma sermayesi oranının net faaliyet karı üzerinde bir etkisinin olup olmadığını incelemiştir. Sonuç olarak; net faaliyet karıyla çalışma sermayesi oranı arasında güçlü pozitif ilişki, nakit dönüşüm süresiyle ise bir ilişki bulunamamıştır. Net faaliyet karı ile alacakların ortalama tahsil süresi arasında negatif ilişki, stok devir süresi ve borç ödeme süresi arasında anlamsız negatif ilişki tespit edilmiştir. Forghani ve diğ. (2013) Tahran Borsasına kayıtlı 56 işletmenin 2003-2007 yılları arasındaki verilerini kullanarak çalışma sermayesi yönetimi ile karlılık performansı ölçütü olarak kullanılan aktif karlılık, özsermaye karlılık ve piyasa performans oranı arasında pozitif ve anlamlı bir ilişkinin olduğunu ispatlamışlardır.

Türkiye'de gerçekleştirilen çalışma sermayesi ve karlılık ilişkisini inceleyen çalışmalar çoğunlukla Borsa İstanbul'da (BIST) işlem gören şirketlerin verileri kullanılarak incelenmiştir. Çalışmalar genellikle belirli bir sektör dâhilinde gerçekleştirilmiştir. Keskin ve Gökalp (2016) gıda ve içecek sektöründe faaliyet gösteren ve Borsa İstanbul'a (BIST) kayıtlı şirketlerin 2009-2013 dönemine ait verilerini kullanarak bir çalışma yapmıştır. Yapılan çalışmada nakit dönüşüm süresinin firma karlılığı üzerinde negatif ama istatistiki olarak anlamlı olmayan, alacak tahsil süresinin ve cari oranın ise negatif ama anlamlı etkiye sahip olduğu görülmüştür. Altan ve Şekeroğlu (2013) Borsa İstanbul'a (BIST) kayıtlı dokuma sanayinde faaliyette bulunan 16 firma üzerinde 2003-2012 dönemi verilerini kullanarak çalışma sermayesi finansman stratejilerinin firma karlıığı üzerine etkilerini araştırmıştır. Çalışmada, atılgan finansman stratejisini takip eden işletmelerin aktif karlılıkları en yüksek, dengeli finansman stratejisini takip eden işletmeler ikinci, muhafazakâr finansman stratejisini takip eden işletmelerin aktif karlılıkları ise son sırada yer almıştır. Karabay (2013) konfeksiyon sanayinin çalışma sermayesinin karlılık üzerindeki etkisini incelemiştir. Bu incelemesinde veri olarak Merkez Bankası tarafından yayınlanan hazır giyim sanayi finansal verilerini kullanmıştır. Hazır giyim işletmelerinin alacakların tahsil süresini kısaltarak, likidite ve karlılık arasında bir denge oluşturarak, varlıklarını sürdürüp karlııklarını arttırabilecekleri sonucuna ulaşılmıştır.

Turizm yazını incelendiğinde, Borsa İstanbul'a (BIST) kayıtı turizm işletmelerinin veri analizi ve anket yoluyla elde edilen verilerin tanımlayıcı istatistik yöntemleriyle yapılan analizleri şeklinde birkaç çalışmaya rastlanılmıştır. Karadeniz ve Kahiloğulları (2013) 191 adet turizm işletmesine anket uygulayarak en yaygın kullanılan finansal oranlar ve önem derecelerini saptamışlardır. Ecer ve Günay (2014) yaptıkları çalışmada Borsa İstanbul'da (BIST) işlem gören dokuz turizm işletmesinin finansal performanslarını Gri İlişkisel Analiz (GIA) yöntemini kullanarak değerlendirmiş ve turizm işletmelerinin finansal performanslarını etkileyen en önemli göstergenin kaldıraç derecesi olduğunu bulmuştur. Özçelik ve Kandemir (2015) TOPSis yöntemini kullanarak Borsa İstanbul'da (BIST) işlem gören 7 turizm şirketinin 2010-2014 dönemine ait finansal performansı likidite, kaldıraç, karlılık ve faaliyet göstergeleri kapsamında değerlendirmiştir. Turizm sektöründe çalışma sermayesi yönetiminin karlılık performansına etkisini ölçmeye dönük benzer bir çalışma Karadeniz ve İskenderoğlu (2011) tarafından gerçekleştirilmiştir. Çalışmada Borsa İstanbul'da (BIST) işlem gören turizm işletmelerinin 2002-2009 yıllarına ait çeyrek dönemlik verileri kullanılarak aktif karlılığı etkileyen değişkenler bütünleşik regresyon (pooled OLS) yöntemiyle analiz edilmiştir. Aktif karlılık üzerinde kaldıraç oranının negatif, ölçek, pazar payı, net işletme sermayesi devir hızı ve aktif devir hızının pozitif, alacak devir hızı ve stok devir hızının ise anlamlı bir etkisinin olmadığı tespit edilmiştir. 
$\mathrm{Bu}$ çalışmanın amacı, çalışma sermayesi yönetiminin karlılık performansı üzerinde etkisini panel veri analizi yöntemiyle analiz etmektir. Çalışmamızda Borsa İstanbul'da (BIST) işlem görüp konaklama sektöründe faaliyet gösteren ve konsolide olmayan mali tablolara sahip 5 adet işletmenin 2005-2015 dönemine ait verilerinden yararlanılmıştır. Dört bölümden oluşan çalışmanın ikinci bölümünde kullanılan veri seti ve ekonometrik model hakkında bilgi verilmekte, üçüncü bölümde analiz bulguları yer almakta, genel bir değerlendirmenin yapıldığı dördüncü bölümle çalışma sona ermektedir.

\section{Araştırmanın Yöntemi}

Çalışmada, Kamu aydınlatma Platformu'nun resmi web sayfasında yer alan ve Borsa İstanbul'da "Otel, Motel, Pansiyon, Kamp ve Diğer"* sektör alt başlığında toplanan 10 adet işletmeden, 2005-2015 yılları arasında faaliyetlerine kesintisiz devam eden ve finansal tabloları konsolide ${ }^{* *}$ olmayan 5 işletmenin çalışma sermayesi unsurlarının karlılık performansı üzerine bir etkisinin olup olmadığı panel veri analizi yardımıyla araştırılmıştır.

Çalışma sermayesi ve karlılık performansını temsil eden değişkenlerin seçimi ve uygulanan yöntem konusunda literatürden yararlanılmıştır (Öz ve Güngör 2007; Saldanlı 2012; Çakır ve Küçükkaplan 2012; Sağlam ve Karaca 2015; Keskin ve Gökalp 2016; Helhel 2016). İşletmelerin 2005-2009 dönemine verileri Borsa İstanbul'un web sayfasında yer alan mali tablolar arşiv (2009 ve Öncesi) kısmından ve 2010-2015 dönemine ait veriler ise Kamu Aydınlatma Platformu'nun ilgili adresinde yer alan finansal tablolardan yararlanılarak hazırlanmıştır.

Çalışmada kullanılan değişkenler Tablo 1'de gösterilmiştir. İşletmelerin faaliyetlerinde karlılıklarını ölçmeye yarayan oranlar genel olarak işletmenin satışları ve yatırımları üzerinden karlılığı gösteren değerlerdir (Ceylan ve Korkmaz 2008: 70). Bu değerler temel olarak iki gruba ayrılmaktadır. Çalışmamızda, işletmenin elde ettiği kar ile kullanılan kaynaklar arasındaki ilişkiyi ortaya koyan yatıım karlılık oranlarından literatürde yaygın olarak tercih edilen iki oran kullanılmış olup, satışlarla karlılığı ilişkilendiren oranlar çalışmamıza dâhil edilmemiştir.

Panel veri analizi zaman boyutuna ait kesit verilerini kullanarak ekonomik ilişkilerin tahmin edilmesine dayanan bir analiz türüdür. Bu analiz, kesitte yer alan gözlemlerin yıllar itibariyle tekrarı söz konusu olduğundan, tekrarlı varyans ve varyans modellerine dayanmaktadır (Öz ve Güngör 2007: 325). Yöntem araştırmacıya, üzerinde çalıştığı serileri hem yatay kesit hem de zaman serisi boyutunda değerlendirme imkânı vermekte olup, kısa zaman serisi verileri üzerinde değişim dinamiklerini analiz etmede önemli bir avantaj ve imkân sağlamaktadır. Söz konusu yöntemde, araştırmada ele alınan değişkenlerin kesitsel boyutunda çok sayıda gözlem, mesela bireyler, ülkeler, firmalar veya ülkeler grubu bir arada incelenmekte ve analiz edilebilmektedir (Saygılı ve diğ. 2006: 90). Panel veri analizi, yatay kesit ve zaman serisi analiz yöntemlerine göre daha karmaşık davranış modellerini oluşturma ve analiz etmeye yararken pek çok analiz yönteminde karşımıza çıkan göz ardı edilen değişkenlerin oluşturduğu sorunları ortadan kaldırmaktadır. Hatalı ölçülen veya gözlemlenemeyen değişkenlerin etkisinin denetlenmesi sağlanabilmektedir (Hsiao ve

\footnotetext{
* 2016 yılı itibariyle sektör alt başlığında 10 adet işletme bulunmaktadır. https://www.kap.org.tr/tr/bist-sirketler 2005 yılından itibaren halka açık şirketler uluslararası finansal raporlama standartlarına göre, finansal tablolarını bağı oldukları grup şirketlerinin finansal tabloları ile konsolide etmek zorundadırlar. Bu sebeple konsolide finansal tablolar sadece ilgili şirketin değil, konsolide edilen diğer şirketlerin de mali bilgilerini içermektedir
} 
diğ. 2012:5). Panel veri Denklem (1) ile ifade edilmektedir. Burada $\mathrm{N}$ birimleri, $\mathrm{t}$ ise zamanı göstermektedir (Pazarlıoğlu ve Gürler 2007: 37):

$Y_{i t}=\beta_{1 i t}+\beta_{2 i t} X_{2 i t}+\ldots \ldots \ldots . .+\beta_{k i t} X_{k i t}+e_{i t} \quad \mathrm{i}=1,2, \ldots . . \mathrm{N} \quad$ ve $\mathrm{t}=1,2, \ldots . . \mathrm{T}$

Tablo 1: Bağımlı ve Bağımsız Değişkenler

\begin{tabular}{|c|c|c|c|}
\hline \multirow{19}{*}{ 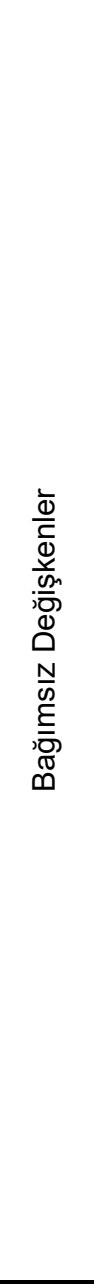 } & Asit-test oranı & AT & $\frac{\text { Dönen var - stoklar }}{\text { k.vadeli borçlar }}$ \\
\hline & \multirow[b]{2}{*}{ Alacak devir hızı oranı } & \multirow{2}{*}{ ALDH } & net kredili sat. \\
\hline & & & ortalama ticari alacaklar \\
\hline & \multirow[b]{2}{*}{ Stok devir hızı oranı } & \multirow{2}{*}{$\mathrm{SDH}$} & sat.maliyeti \\
\hline & & & $\overline{\text { ortalama stoklar }}$ \\
\hline & Cari oran & $\mathrm{CO}$ & $\frac{\text { d.varl. }}{\text { kvyk }}$ \\
\hline & Nakit oranı & NO & $\frac{\text { kasa }+ \text { bankalar }+ \text { menkul k. }}{\text { kvyk }}$ \\
\hline & \multirow[b]{2}{*}{ Aktif devir hızı oranı } & \multirow{2}{*}{$\mathrm{AKDH}$} & net sat. \\
\hline & & & toplam aktifler \\
\hline & \multirow[b]{2}{*}{ Kısa vadeli borç oranı } & \multirow{2}{*}{$\mathrm{KBO}$} & $\mathrm{kvb}$ \\
\hline & & & toplam aktif \\
\hline & \multirow{2}{*}{$\begin{array}{c}\text { Net işletme sermayesi } \\
\text { oranı }\end{array}$} & \multirow{2}{*}{ NIS } & dönem varl. - kvyk \\
\hline & & & satislar \\
\hline & \multirow{2}{*}{$\begin{array}{c}\text { İşletme sermayesi devir } \\
\text { hızı }\end{array}$} & \multirow{2}{*}{$\mathrm{ISDH}$} & net sat. \\
\hline & & & ortalama net isletme sermayesi \\
\hline & \multirow{2}{*}{$\begin{array}{c}\text { Kısa vadeli borç-toplam } \\
\text { borç oranı }\end{array}$} & \multirow{2}{*}{ KVBTB } & kvyk \\
\hline & & & toplam borc \\
\hline & \multirow[b]{2}{*}{ Toplam borç oranı } & \multirow{2}{*}{ TBO } & kvyk + uvyk \\
\hline & & & toplam aktif \\
\hline \multirow{4}{*}{ 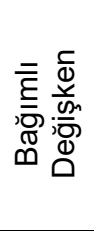 } & \multirow[b]{2}{*}{ Aktif Karlılığı } & \multirow{2}{*}{ AKK } & donem karı \\
\hline & & & toplam aktif \\
\hline & \multirow[b]{2}{*}{ Öz sermaye karlılığı } & \multirow{2}{*}{ OZK } & net kar \\
\hline & & & oz sermaye \\
\hline
\end{tabular}

Panel analizlerinin yapılabilmesi için kullanılan serilerin durağan olması önemlidir. Bunun için serilerin zaman içinde sabit varyans ve ortalama özelliğine sahip olmaları gerekmektedir. Durağanlık şartı gerçekleşmediğinde, değişkenler arasında sahte ilişkiler ortaya çıkmaktadır. Panel veri analizlerinde durağanlık testlerinden birim kök Dickey Fuller (ADF) ve Philips Peron (PP) test istatistiklerini kullanan Levin-LinChu (LLC) ve bunun geliştirilmiş hali olan Im-Pesaran-Shin (IPS) testleri en çok kullanılan testlerdir (Şahin 2011: 128). 
Değişkenler arasında uzun dönemde karşılıklı bir ilişkinin olup olmadığını tespit etmek benzer tüm analiz yöntemleri için neredeyse bir zorunluluktur. Bu amaçla, Panel veri analizi uygulamalarında, Pedroni ve Kao eşbütünleşme testlerinden yararlanılmaktadır. Heterojen yatay kesitler için seriler arasındaki eş bütünleşmenin varlığını test etmek için kullanılan eşbütünleşme testi Pedroni (2004) tarafından geliştirilmiştir. Testin boş hipotezi "seriler arasında eşbütünleşme yok" şeklindedir İki test grubundan oluşan Pedroni eşbütünleşme analizinin birden fazla açıklayıcı değişkene ve eşbütünleşme vektörünün yatay kesitler arasında heterojenliğine izin vermesi, güçlü yönleri olarak kabul edilmektedir (Göçer 2013: 131).

Nedensellik analizinin hata düzeltme modeliyle (VECM) yapılması çok yaygın olup, bu yöntem verinin kısa ve uzun dönem dinamiklerini birbirinden ayırt etme imkânı da sunar ve hata düzeltme modeli Denklem (2) ile ifade edilir (Kıran 2007: 273).

$$
\Delta X_{t}=\alpha+\sum_{i=1}^{M} \beta_{i} \Delta X_{t-i}+\sum_{i=1}^{n} \gamma_{i} \Delta Y_{t-i}+\sum_{i=1}^{p} \psi \Delta Z_{t-i}+\lambda E C_{t-1}+e_{t}
$$

Aralarında nedensellik ilişkisi olan değişkenlerin hata düzeltme mekanizmalarına ait olan istatistiklerin negatif ve istatistiki bakımdan anlamlı olması, ilgili değişkenlerin kendi denge değerlerine yakınsayabileceklerini ve kısa dönemde ortaya çıkabilecek olan dengesizliklerin uzun dönemde giderilebileceğini ortaya koymuştur (Akıncı ve diğ. 2014: 68). Panel veri regresyonundaki sabit terim ve bağımsız değişkenlerin katsayıları birim vezamana göre aldığı değerlere bağlı olarak farklı panel veri modelleri ile tahmin edilmektedir. Bu modeller arasında en çok kullanılanlar "sabit etkili model" ve "rassal etkili modeldir (Keskin ve Gökalp 2016: 20). Ancak bu iki model arasında tercih yapılacak bir tercih için Haussman test istatistiği yöntemine intiyaç vardır. Bu testte boş hipotez bireysel etkilerin modeldeki diğer regresörlerle ilişkisiz olduğunu (rassal etkinin varlığını) belirtmektedir. Boş hipotezin reddedilmesi ise sabit etki modelinin rassal etki modeline tercih edilmesi gerektiğini göstermektedir (Berke 2009: 41).

\section{Uygulama Bulguları}

Serilerin durağanlığı Levin-Lin-Chu (LLC) ve Im-Pesaran-Shin (IPS) tarafından geliştirilen panel birim kök testleriyle tespit edilmiştir. Tablo 2 incelendiğinde değişkenlerden biri hariç (ISDH-işletme sermayesi devir hızı) tamamının birinci fark düzeylerinde durağan olduğu görülmektedir.

\section{Tablo 2: Panel Birim Kök Testi Sonuçları}

\begin{tabular}{|l|r|r|r|r|}
\hline & \multicolumn{2}{|c|}{ LLC $\boldsymbol{t}$ İstatistiği } & \multicolumn{2}{c|}{ IPS $\boldsymbol{W}$ İstatistiği } \\
\hline Değişken & Düzey Değerleri & \multicolumn{1}{c|}{ Birinci Farkları } & \multicolumn{1}{c|}{ Düzey Değerleri } & \multicolumn{1}{c|}{ Birinci Farkları } \\
\hline AKK & $19.986(0.029)$ & $43.626(0.000)^{*}$ & $20.118(0.028)$ & $52.743(0.000)^{*}$ \\
\hline OZK & $17.670(0.060)$ & $37.021(0.000)^{*}$ & $11.744(0.302)$ & $42.745(0.000)^{*}$ \\
\hline AT & $18.305(0.05)$ & $33.587(0.000)^{*}$ & $16.998(0.074)$ & $45.989(0.000)^{*}$ \\
\hline ALDH & $13.681(0.188)$ & $49.590(0.000)^{*}$ & $18.921(0.041)$ & $28.221(0.001)^{*}$ \\
\hline AKDH & $9.508(0.484)$ & $30.239(0.000)^{*}$ & $9.047(0.527)$ & $32.378(0.000)^{*}$ \\
\hline CO & $13.014(0.222)$ & $25.117(0.005)^{*}$ & $13.964(0.174)$ & $39.089(0.000)^{*}$ \\
\hline ISDH & $54.176(0.000)^{*}$ & & $65.050(0.000)^{*}$ & \\
\hline KBO & $13.384(0.203)$ & $29.253(0.001)^{*}$ & $13.902(0.177)$ & $33.205(0.000)^{*}$ \\
\hline KVBTBO & $19.791(0.031)$ & $40.448(0.000)^{*}$ & $33.844(0.000)^{*}$ & $58.396(0.000)^{*}$ \\
\hline NIS & $14.129(0.167)$ & $34.071(0.000)^{*}$ & $24.224(0.007)^{*}$ & $44.422(0.000)^{*}$ \\
\hline NO & $21.326(0.018)$ & $27.638(0.002)^{*}$ & $24.778(0.005)^{*}$ & $38.186(0.000)^{*}$ \\
\hline SDH & $16.048(0.098)$ & $45.331(0.000)^{*}$ & $21.982(0.015)$ & $62.927(0.000)^{*}$ \\
\hline TBO & $18.037(0.054)$ & $32.441(0.000)^{*}$ & $20.452(0.025)$ & $20.748(0.022)$ \\
\hline
\end{tabular}

Not: * işareti ilgili değişkenin \%1 önem düzeyinde durağan olduğunu yansıtmaktadır. 
Tablo 3: Pedroni Eş-bütünleşme Test Sonuçları

\begin{tabular}{|c|c|c|c|c|c|c|c|c|}
\hline & Test & Panel $v$ & Panelrho & Panel PP & Panel ADF & $\begin{array}{l}\text { Grup } \\
\text { rho }\end{array}$ & Grup PP & Grup ADF \\
\hline \multirow{2}{*}{ 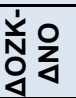 } & İstatistik & $-0,871$ & $-2,872^{\star \star}$ & $12,050^{\star *}$ & $-8,623^{\star *}$ & $-0,518$ & $-6,458^{* \star}$ & $-6,491^{\star *}$ \\
\hline & Olasılık & 0,808 & 0,002 & 0,000 & 0,000 & 0,302 & 0,000 & 0,000 \\
\hline \multirow{2}{*}{ 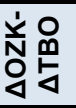 } & İstatistik & $-0,735$ & $-3.430^{\star *}$ & $-7.066^{\star *}$ & $-7.066^{\star \star}$ & $-0,972$ & $-6.338^{* *}$ & $-6.159^{\star \star}$ \\
\hline & Olasılık & 0,769 & 0,000 & 0,000 & 0,000 & 0,166 & 0,000 & 0,000 \\
\hline \multirow{2}{*}{ 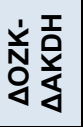 } & İstatistik & 0,149 & $-2.067^{*}$ & $-8.053^{* *}$ & $-6.608^{* *}$ & $-0,736$ & $-7.604^{* *}$ & $-6.212^{* *}$ \\
\hline & Olasılık & 0,440 & 0,019 & 0,000 & 0,000 & 0,231 & 0,000 & 0,000 \\
\hline \multirow{2}{*}{ 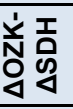 } & İstatistik & $-1,543$ & $-3,067^{\star *}$ & $-9,093^{* *}$ & $-4,226^{\star *}$ & $-0,855$ & $-7,960^{\star *}$ & $-2,159^{*}$ \\
\hline & Olasılık & 0,939 & 0,001 & 0,000 & 0,000 & 0,196 & 0,000 & 0,015 \\
\hline \multirow{2}{*}{ 峁选 } & İstatistik & $2,410^{* *}$ & $-1,968^{*}$ & $-2,404^{* *}$ & $-2,536^{* *}$ & $-0,461$ & $-4,423^{* *}$ & $-4,481^{* *}$ \\
\hline & Olasılık & 0,008 & 0,024 & 0,008 & 0,005 & 0,322 & 0,000 & 0,000 \\
\hline \multirow{2}{*}{ 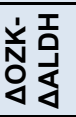 } & İstatistik & 1,154 & $-3,114^{\star *}$ & $-9,897^{\star *}$ & $-8,174^{* *}$ & $-1,187$ & $-9,956^{* *}$ & $-8,023^{\star *}$ \\
\hline & Olasılık & 0,124 & 0,000 & 0,000 & 0,000 & 0,117 & 0,000 & 0,000 \\
\hline \multirow{2}{*}{$\begin{array}{l}\text { Ň O } \\
\text { No }\end{array}$} & İstatistik & $-0,925$ & $-2,356^{\star *}$ & $-14,829^{\star *}$ & $-8,677^{* *}$ & $-0,689$ & $-7,775^{\star *}$ & $-6,241^{* *}$ \\
\hline & Olasılık & 0,822 & 0,009 & 0,000 & 0,000 & 0,245 & 0,000 & 0,000 \\
\hline \multirow{2}{*}{$\begin{array}{l}\dot{⿱ 亠 乂} \\
\text { ơ } \\
\text { ô }\end{array}$} & İstatistik & $-0,477$ & $-4,921^{* *}$ & $-9,328^{* *}$ & $-7,955^{\star *}$ & $-1,446$ & $-6,302^{* *}$ & $-5,687^{* *}$ \\
\hline & Olasılık & 0,683 & 0,000 & 0,000 & 0,000 & 0,074 & 0,000 & 0,000 \\
\hline \multirow{2}{*}{ 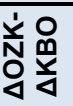 } & İstatistik & $-2,443$ & $-1,120$ & $-31,747^{* *}$ & $-11,433^{\star *}$ & 0,576 & $-11,547^{* *}$ & $-6,166^{* *}$ \\
\hline & Olasılık & 0,993 & 0,131 & 0,000 & 0,000 & 0,717 & 0,000 & 0,000 \\
\hline \multirow{2}{*}{ 它息 } & İstatistik & $-1,626$ & $-3,085^{\star *}$ & $-8,967^{\star *}$ & $-7,855^{\star *}$ & $-0,818$ & $-6,475^{\star *}$ & $-5,997^{\star *}$ \\
\hline & Olasılık & 0,948 & 0,001 & 0,000 & 0,000 & 0,207 & 0,000 & 0,000 \\
\hline \multirow{2}{*}{ 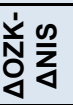 } & İstatistik & $-2,906$ & 1,397 & $-8,467^{\star *}$ & $-7,769^{* *}$ & 1,262 & $-5,609^{* *}$ & $-4,191^{* *}$ \\
\hline & Olasılık & 0,998 & 0,918 & 0,000 & 0,000 & 0,896 & 0,000 & 0,000 \\
\hline \multirow{2}{*}{ 安o } & İstatistik & $-1,048$ & $-2.692^{\star *}$ & $-8.467^{\star *}$ & $-7.769^{* *}$ & 1,262 & $-5.609^{* *}$ & $-4.191^{\star *}$ \\
\hline & Olasılık & 0,852 & 0,003 & 0,000 & 0,000 & 0,896 & 0,000 & 0,000 \\
\hline \multirow{2}{*}{$\begin{array}{l}\text { 安。 } \\
\text { 安点 }\end{array}$} & İstatistik & 1,213 & $-2.162^{*}$ & $-5.157^{\star *}$ & $-5.605^{\star *}$ & $-0,813$ & $-7.995^{\star *}$ & $-6.615^{\star *}$ \\
\hline & Olasılık & 0,112 & 0,015 & 0,000 & 0,000 & 0,208 & 0,000 & 0,000 \\
\hline \multirow{2}{*}{ 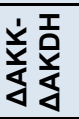 } & İstatistik & 0,149 & $-2,067^{*}$ & $-8,053^{* *}$ & $-6,608^{* *}$ & $-0,736$ & $-7,604^{* *}$ & $-6,212^{* *}$ \\
\hline & Olasılık & 0,440 & 0,019 & 0,000 & 0,000 & 0,231 & 0,000 & 0,000 \\
\hline \multirow{2}{*}{ 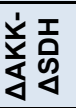 } & İstatistik & $2,723^{* *}$ & $-2,496^{* *}$ & $-6,815^{\star *}$ & $-7,918^{* *}$ & $-1,155$ & $-8,743^{\star *}$ & $-7,918^{\star *}$ \\
\hline & Olasılık & 0,003 & 0,006 & 0,000 & 0,000 & 0,124 & 0,000 & 0,000 \\
\hline \multirow{2}{*}{ 安ヶ } & İstatistik & $2.504^{\star \star}$ & $-1.863^{*}$ & $-4.712^{\star *}$ & $-6.146^{\star *}$ & $-0,53$ & $-5.660^{* *}$ & $-5.323^{* *}$ \\
\hline & Olasılık & 0,006 & 0,031 & 0,000 & 0,000 & 0,297 & 0,000 & 0,000 \\
\hline \multirow{2}{*}{ 安吉 } & İstatistik & $-0,820$ & $-2,859^{\star *}$ & $-8,467^{\star *}$ & $-7,769^{* *}$ & 1,262 & $-5,609^{\star *}$ & $-4,191^{* *}$ \\
\hline & Olasılık & 0,794 & 0,002 & 0,000 & 0,000 & 0,896 & 0,000 & 0,000 \\
\hline \multirow{3}{*}{ 安 } & İstatistik & 0,884 & $-2,537^{\star *}$ & $-16,073^{\star *}$ & $-9,393^{* *}$ & $-1,061$ & $-15,196^{* *}$ & $-8,460^{\star *}$ \\
\hline & Olasılık & 0,188 & 0,005 & 0,000 & 0,000 & 0,144 & 0,000 & 0,000 \\
\hline & Olasılık & 0,018 & 0,007 & 0,000 & 0,000 & 0,141 & 0,000 & 0,000 \\
\hline
\end{tabular}


Tablo 3'ün Devamı

\begin{tabular}{|c|c|c|c|c|c|c|c|c|}
\hline \multirow{2}{*}{ 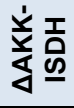 } & İstatistik & 0,471 & $-2.206^{*}$ & $-7.207^{* *}$ & $-6.891^{* *}$ & $-0,694$ & $-8.948^{* *}$ & $-6.641^{* *}$ \\
\hline & Olasılık & 0,318 & 0,013 & 0,000 & 0,000 & 0,243 & 0,000 & 0,000 \\
\hline \multirow{2}{*}{ 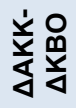 } & İstatistik & 1,213 & $-2.162^{*}$ & $-5.157^{\star *}$ & $-5.605^{\star *}$ & $-0,814$ & $-7.995^{\star *}$ & $-6.615^{\star *}$ \\
\hline & Olasılık & 0,112 & 0,015 & 0,000 & 0,000 & 0,208 & 0,000 & 0,000 \\
\hline \multirow{2}{*}{ 案 } & İstatistik & $2.669^{* *}$ & $-2.470^{* *}$ & $-7.295^{\star *}$ & $-7.713^{* *}$ & $-1,017$ & $-9.201^{* *}$ & $-7.713^{* *}$ \\
\hline & Olasılık & 0,003 & 0,006 & 0,000 & 0,000 & 0,154 & 0,000 & 0,000 \\
\hline$\frac{\dot{x}}{\frac{x}{2}} \frac{\infty}{8}$ & İstatistik & $2.100^{*}$ & $-2.457^{\star *}$ & $-5.192^{\star *}$ & $-5.360^{* *}$ & $-1,078$ & $-7.038^{\star *}$ & $-5.897^{\star *}$ \\
\hline
\end{tabular}

Not: $\Delta$ terimi, değişkenin 1.dereceden farkını göstermektedir. ${ }^{*}$ ve ${ }^{* *}$ işaretleri ilgili istatistik değerlerinin sırasıyla $\% 5$ ve $\% 1$ önem düzeyinde anlamlı olduklarını yansıtmaktadır. Optimum gecikme uzunluğunun belirlenmesinde SIC kriteri dikkate alınmış, Bartlett ve Newey-West bant genişliği kriterlerinden yararlanılmıştır.

Modelde dikkate alınan değişkenler arasındaki uzun dönemli ilişkilerin tespit edilebilmesi için Pedroni (2004) testi yapılmış ve elde edilen sonuçlar Tablo 3'de sunulmuştur. Tablo 3' de verilen Pedroni eşbütünleşme testi sonuçlarına göre H0 hipotezi (seriler arasında eşbütünleşme yoktur) reddedilmiştir. Çünkü genel olarak değerlendirildiğinde, Pedroni eşbütünleşme testindeki hem panel hem de grup istatistiklerini oluşturan yedi testin çoğunluğu \% 1 ve \% 5 seviyesinde istatistiksel olarak anlamlıdır. Dolayısıyla alternatif hipotez (seriler arasında eşbütünleşme vardır) önermesi kabul edilmiştir (Yardımcıoğlu ve Gülmez 2013: 154). Bu durum sahte regresyon probleminin yaşanmayacağını ve değişkenler arasında en azından tek yönlü bir nedensellik ilişkisinin geçerli olabileceğini göstermektedir.

Seriler arasında nedensellik ilişkisi VECM modeli testiyle incelenmiş ve bulgular Tablo 4'te sunulmuştur. Analiz sonuçları beklentileri karşılar nitelikte karlılık değişkenleri ile çalışma sermayesi değişkenleri arasında en azından tek yönlü olarak sebep sonuç ilişkisinin var olduğunu göstermektedir. Karlılık değişkenlerinden öz sermaye karlılığının (OZK) aktif devir hızı (AKDH), alacak devir hızı (ALDH), cari oran (CO), kısa vadeli borç (KBO), nakit oran (NO) ve toplam borç oranıyla(TBO), diğer bağımlı değişken aktif karlılığın (AKK) ise sadece asit-test oranıyla (AT) çift yönlü sebep sonuç ilişkisi bulunmaktadır.

Sabit ve rassal etkili model sonuçları tahmin etmek için öncelikle uygun modeli seçebilmek için Haussman test istatistiği yöntemine başvurulmuştur. Tablo 5 de verilen Haussman test sonuçları, "rassal etkiler tahmincisi uygundur" sıfır hipotezinin 0.05 anlamlılık düzeyinde kabul edildiği ve her iki bağımlı değişken için rassal etkiler modelinin daha tutarlı ve etkin olduğunu göstermektedir. Buna istinaden rassal etkili modeller tahmin edilmiş ve sonuçları Tablo 6'da sıralanmıştır.

Tablo 4: VECM Nedensellik Testi Sonuçları

\begin{tabular}{|l|c|l|l|}
\hline Değiş̧kenler & Nedenselliğin Yönü & ECT & p-değeri \\
\hline$\triangle$ AKDH- $\triangle \mathrm{OZK}$ & $\rightarrow$ & $-1.439^{*}$ & 0.000 \\
\hline$\Delta \mathrm{OZK}-\triangle \mathrm{AKDH}$ & $\rightarrow$ & $-0.933^{*}$ & 0.000 \\
\hline$\Delta \mathrm{AT}-\Delta \mathrm{OZK}$ & - & -0.187 & 0.289 \\
\hline$\Delta \mathrm{OZK}-\Delta \mathrm{AT}$ & $\rightarrow$ & $-1.234^{*}$ & 0.000 \\
\hline$\triangle \mathrm{ALDH}-\triangle \mathrm{OZK}$ & $\rightarrow$ & $-1.498^{*}$ & 0.002 \\
\hline
\end{tabular}


Tablo 4 'ün Devamı

\begin{tabular}{|c|c|c|c|}
\hline$\Delta \mathrm{OZK}-\triangle \mathrm{ALDH}$ & $\rightarrow$ & $-0.087^{*}$ & 0.000 \\
\hline$\Delta \mathrm{CO}-\triangle \mathrm{OZK}$ & $\rightarrow$ & $-0.916^{* * *}$ & 0.053 \\
\hline$\Delta \mathrm{OZK}-\Delta \mathrm{CO}$ & $\rightarrow$ & $-0.539^{*}$ & 0.010 \\
\hline ISDH- $\triangle \mathrm{OZK}$ & - & -0.000 & 0.906 \\
\hline$\triangle \mathrm{OZK}-\mathrm{ISDH}$ & $\rightarrow$ & $-0.757^{\star}$ & 0.000 \\
\hline$\triangle \mathrm{KVBTB}-\triangle \mathrm{OZK}$ & - & 0.006 & 0.634 \\
\hline$\Delta$ OZK- $\Delta K V B T B$ & $\rightarrow$ & $-1.720^{*}$ & 0.000 \\
\hline$\Delta \mathrm{KBO}-\triangle \mathrm{OZK}$ & $\rightarrow$ & $-0.090^{*}$ & 0.000 \\
\hline$\Delta \mathrm{OZK}-\Delta \mathrm{KBO}$ & $\rightarrow$ & $-0.763^{\star \star \star}$ & 0.053 \\
\hline$\Delta \mathrm{NIS}-\triangle \mathrm{OZK}$ & - & 0.888 & 0.001 \\
\hline$\Delta \mathrm{OZK}-\Delta \mathrm{NIS}$ & $\rightarrow$ & $-2.488^{*}$ & 0.000 \\
\hline$\Delta \mathrm{NO}-\triangle \mathrm{OZK}$ & $\rightarrow$ & $-0.603^{* * *}$ & 0.094 \\
\hline$\Delta \mathrm{OZK}-\Delta \mathrm{NO}$ & $\rightarrow$ & $-0.735^{\star *}$ & 0.013 \\
\hline$\Delta \mathrm{SDH}-\Delta \mathrm{OZK}$ & $\rightarrow$ & $-1.603^{*}$ & 0.002 \\
\hline$\Delta \mathrm{OZK}-\Delta \mathrm{SDH}$ & - & -0.000 & 0.856 \\
\hline$\triangle \mathrm{TBO}-\triangle \mathrm{OZK}$ & $\rightarrow$ & $-1.406^{*}$ & 0.003 \\
\hline$\triangle \mathrm{OZK}-\Delta$ TBO & $\rightarrow$ & $-0.497^{*}$ & 0.001 \\
\hline$\triangle \mathrm{AKDH}-\triangle \mathrm{AKK}$ & $\rightarrow$ & $-1.103^{\star \star \star}$ & 0.052 \\
\hline$\triangle \mathrm{AKK}-\triangle \mathrm{AKDH}$ & - & -0.448 & 0.153 \\
\hline$\Delta$ AT- $\triangle \mathrm{AKK}$ & $\rightarrow$ & $-1.272^{*}$ & 0.000 \\
\hline$\Delta \mathrm{AKK}-\Delta \mathrm{AT}$ & $\rightarrow$ & $-0.517^{* *}$ & 0.025 \\
\hline$\triangle \mathrm{ALDH}-\triangle \mathrm{AKK}$ & $\rightarrow$ & $-1.916^{*}$ & 0.000 \\
\hline$\triangle \mathrm{AKK}-\triangle \mathrm{ALDH}$ & - & -0.035 & 0.588 \\
\hline$\Delta \mathrm{CO}-\Delta \mathrm{AKK}$ & $\rightarrow$ & $-2.862^{*}$ & 0.000 \\
\hline$\Delta \mathrm{AKK}-\Delta \mathrm{CO}$ & - & -0.066 & 0.392 \\
\hline ISDH- $\triangle \mathrm{AKK}$ & - & 0.008 & 0.797 \\
\hline$\triangle \mathrm{AKK}-\mathrm{ISDH}$ & $\rightarrow$ & $-0.765^{*}$ & 0.000 \\
\hline$\Delta K V B T B-\triangle A K K$ & - & -0.427 & 0.169 \\
\hline$\Delta \mathrm{AKK}-\Delta \mathrm{KVBTB}$ & $\rightarrow$ & $-1.436^{*}$ & 0.003 \\
\hline$\Delta \mathrm{KBO}-\Delta \mathrm{AKK}$ & $\rightarrow$ & $-2.145^{*}$ & 0.000 \\
\hline$\triangle \mathrm{AKK}-\Delta \mathrm{KBO}$ & - & 0.011 & 0.909 \\
\hline$\Delta \mathrm{NIS}-\Delta \mathrm{AKK}$ & $\rightarrow$ & $-1.554^{\star}$ & 0.000 \\
\hline$\Delta$ AKK- $\Delta$ NIS & - & -0.297 & 0.261 \\
\hline$\Delta \mathrm{NO}-\Delta \mathrm{AKK}$ & $\rightarrow$ & $-1.714^{*}$ & 0.000 \\
\hline$\Delta \mathrm{AKK}-\Delta \mathrm{NO}$ & - & -0.191 & 0.246 \\
\hline$\Delta \mathrm{SDH}-\triangle \mathrm{AKK}$ & $\rightarrow$ & $-2.153^{*}$ & 0.000 \\
\hline$\Delta \mathrm{AKK}-\Delta \mathrm{SDH}$ & - & 0.134 & 0.217 \\
\hline$\Delta \mathrm{TBO}-\Delta \mathrm{AKK}$ & - & -0.311 & 0.674 \\
\hline$\triangle \mathrm{AKK}-\Delta \mathrm{TBO}$ & $\rightarrow$ & $-1.008^{*}$ & 0.003 \\
\hline
\end{tabular}

Not: $\Delta$ terimi, değişkenin 1.dereceden farkını göstermektedir. ${ }^{*},{ }^{* *}$ ve ${ }^{* * *}$ işaretleri ilgili istatistik değerlerinin sırasıyla \%5, \%1 ve \%10 önem düzeyinde anlamlı olduklarını yansıtmaktadır. ECT eşbütünleşme denkleminden elde edilen hata düzeltme terimi katsayısını ifade etmektedir. 
Tablo 5: Hausman Test İstatistiği

\begin{tabular}{|c|c|c|}
\hline Karlılık Değişkeni & OZK & AKK \\
\hline Ki-kare değeri & 0.199 & 0.273 \\
\hline Olasılık değeri & 0.995 & 0.872 \\
\hline
\end{tabular}

Tablo 6'da görüldüğü üzere; aktif karlılık, alacak ve aktif devir hızından istatistiki olarak anlamlı ve pozitif, net işletme sermayesi ve toplam borç oranından negatif yönde etkilenmekte, diğer çalışma sermayesi değişkenlerinden etkilenmemektedir. Sağlam ve Karaca (2015) net işletme sermayesi oranı, aktif ve alacak devir hızının aktif karlılığı pozitif, Öz ve Güngör (2007) ve Agha (2014) ise alacak ve stok devir hızının aktif karlılığı negatif etkilediği sonucuna ulaşmışlardır. Sağlam ve Karaca (2015) ve Agha (2014)'da cari oranın aktif karlııı oranı ile ilişkisinin olmadığını tespit etmişlerdir. Yücel ve Kurt (2002), Çakır ve Küçükkaplan (2012) toplam borç oranın (kaldıraç oranı) aktif karlılığı negatif etkilediğini bulmuştur. Bu sonuç çalışmamızın sonucuyla örtüşmektedir. Illaveten, Çakır ve Küçükkaplan (2012) cari oranın aktif karlılığı negatif, asit-test oranının ise pozitif etkilediğini, öz sermaye karlılığıyla toplam borç (kaldıraç) ve cari oran arasında bir ilişki olmadığını tespit etmiştir. Sağlam ve Karaca (2015) öz sermaye karlılığının toplam borç oranından (kaldıraç) negatif, net işletme sermayesi, aktif ve alacak devir hızı oranından pozitif yönde etkilendiği sonucuna ulaşmıştır.

Tablo 6: Rassal Etkili Model Tahmin Sonuçları

\begin{tabular}{|c|c|c|c|c|c|c|}
\hline & \multicolumn{6}{|c|}{ BAĞIMLI DEĞIŞKENLER } \\
\hline & \multicolumn{3}{|c|}{$\Delta \mathrm{AKK}$} & \multicolumn{3}{|c|}{$\Delta$ OZK } \\
\hline & Katsayı & t-istatistiği & $\begin{array}{l}\text { Olasılık } \\
\text { değeri }\end{array}$ & Katsayı & t-istatistiği & $\begin{array}{c}\text { Olasılık } \\
\text { değeri }\end{array}$ \\
\hline$\Delta \mathrm{AT}$ & 0.010 & 0.913 & 0.367 & -0.082 & -0.418 & 0.678 \\
\hline$\triangle \mathrm{ALDH}$ & 0.002 & 2.952 & $0.005^{\star *}$ & 0.014 & 1.266 & 0.213 \\
\hline$\triangle \mathrm{AKDH}$ & 0.320 & 2.156 & $0.037^{*}$ & 3.107 & 1.125 & 0.267 \\
\hline$\Delta \mathrm{CO}$ & -0.003 & -0.378 & 0.708 & -0.008 & -0.056 & 0.956 \\
\hline İSDH & $7.26 \mathrm{E}-5$ & 0.424 & 0.574 & 1.49E-05 & 0.009 & 0.993 \\
\hline$\Delta \mathrm{KBO}$ & -0.261 & -1.274 & 0.674 & 1.143 & 0.568 & 0.572 \\
\hline$\Delta \mathrm{KVBTB}$ & 0.020 & 0.241 & 0.209 & -0.580 & -0.729 & 0.469 \\
\hline$\Delta \mathrm{NIS}$ & -0.012 & -2.878 & $0.006^{* *}$ & -0.277 & -6.618 & $0.000^{* *}$ \\
\hline$\Delta \mathrm{NO}$ & $1.49 \mathrm{E}-06$ & 0.001 & 0.999 & -0.068 & -0.457 & 0.650 \\
\hline$\Delta \mathrm{SDH}$ & -0.001 & -1.356 & 0.181 & -0.002 & -0.335 & 0.739 \\
\hline$\triangle \mathrm{TBO}$ & -0.956 & -7.201 & $0.000^{* *}$ & -7.706 & -3.269 & $0.002^{* \star}$ \\
\hline
\end{tabular}
yansıtmaktadır.

\section{Sonuç ve Değerlendirme}

Çalışmada Aydınlatma Platformunun resmi web sayfasında yer alan ve Borsa İstanbul'da (BIST) "Otel, Motel, Pansiyon, Kamp ve Diğer" sektör alt başlığı altında faaliyet gösteren, finansal tabloları konsolide olmayan 5 işletmenin 2005-2015 yıllık verileri kullanılarak çalışma sermayelerinin karlılık performansı üzerine bir etkisinin olup olmadığı panel veri analizi yöntemiyle test edilmiş ve elde edilen modele bağlı olarak aşağıdaki bulgulara ulaşılmıştır.

- Çalışma sermayesinin tüm değişkenleri ile karlılık değişkenleri arasında en azından tek yönlü olarak sebep sonuç ilişkisi vardır. Karlılık değişkenlerinden öz sermaye karlılığının (OZK) aktif devir hızı (AKDH), alacak devir hızı (ALDH), cari (CO), kısa 
vadeli borç (KBO), nakit (NO) ve toplam borç oranıyla (TBO), aktif karlılığın (AKK) ise sadece asit-test oranıyla (AT) çift yönlü sebep sonuç ilişkisi bulunmaktadır.

- Karlılık performansını gösteren oranlardan aktif karlılık (AKK), aktif (AKDH) ve alacak devir hızı (ALDH) oranından pozitif, net işletme sermayesi (NIS) ve toplam borç oranından (TBO) negatif etkilenmektedir. Bu sonuç nedensellik analizinin sonuçları ile örtüşmemektedir.

- Net işletme sermayesi (NIS) ve toplam borç oranı (TBO) öz sermaye karlılığını (OZK)negatif etkilemektedir. Toplam borç oranından özsermaye karlılık oranına doğru bir nedensellik ilişkisi söz konusu olduğu için bu bulgu nedensellik analizini teyit etmektedir.

- Her iki karlılık değişkenini etkileyen çalışma sermayesi oranları net işletme sermayesi(NIS) ve toplam borç oranı (TBO)'dır.

- Çalışma sermayesi değişkenlerinden asit-test (AT), stok devir hızı (SDH), cari (CO), nakit (NO), işletme sermayesi devir hızı (ISDH), kısa vadeli borcun toplam borca oranı (KVBTB) her iki karlılık değişkenleri üzerinde bir etki oluşturmamaktadır.

Genel bir değerlendirme yapıldığında; Borsa İstanbul'da konaklama sektöründe faaliyet gösteren işletmelerin fazla borçlanarak yüksek kaldıraçtan yararlanması onların aleyhinedir. Bunun nedeni olarak, yüksek kaldıraçlı işletmelerin finansal riskinin yükselmesi nedeniyle kaynak bulmasının zorlaşacağı, dolayısıyla borçlanma maliyetinin yükseleceği ve işletme karlılığını olumsuz etkileyebileceği söylenebilir. Net işletme sermayesi oranının karlılığı azaltıcı bir etkisinin olması, incelenen dönemde güçlü bir likidite yapısına sahip olma nedeniyle borçlarını zamanında ödemenin getirdiği avantajın, kaynakların bir kısmının atıl kalması nedeniyle oluşan alternatif maliyetin altında olması durumuyla izah edilebilir. Alacak devir hızının karlılığı arttırma etkisi, konaklama işletmelerinde alacak yönetiminin sıkı ve alacaklara tanınan vadenin kısaltılmasının satışları azaltmadığı ve işletme sermayesi için ek bir finansmana intiyaç duyulmaması nedeniyle kısa vadeli borçlanma maliyetinin düşük olacağı, dolayısıyla karı olumlu etkileyebileceğini teyit etmektedir. Aktif devir hızı ve karılık arasındaki pozitif ilişki, konaklama sektöründe faaliyet gösteren işletmelerin tam kapasite ile çalışamaması, siparişlerin karşılanamaması veya ekonomik ve politik konjonktür nedeniyle satış fırsatlarının kaçırılması sonucu satış gelirlerinin ve beraberinde karlılığın azalacağını göstermektedir.

Analize dahil edilen diğer çalışma sermayesi değişkenlerinin karlıı̆ga istatistiki olarak bir etkisinin olmaması, konaklama sektöründe faaliyet gösteren şirketlerin uyguladıkları çalışma sermayesi unsurlarını optimal seviyede kullanma ve yönetme becerisine sahip olmadıklarından gerekli faydayı elde edip karlıı̆ga dönüştüremediklerinin bir göstergesi olabilir.

Çalışma sadece halka açık konaklama sektöründe faaliyet gösteren işletmeleri kapsamaktadır. İleride yapılacak çalışmalarda Avrupa, Asya ve Amerika borsalarında halka açık konaklama işletmelerinin çalışma sermayesi yapılarının karlılıkla ilişkisi analiz edilerek gruplar arasındaki farklılıklar ve benzerlikler tespit edilerek sektörle ilgili bazı çıkarımlar yapılabilir.

\section{Kaynakça}

Ademola, O.J. (2014), 'Working Capital Management and Profitability of Selected Quoted Food and Beverages Manufacturing Firms in Nigeria', European Journal of Accounting Auditing and Finance Research, 2, 3

Agha, H. (2014), 'Impact of Working Capital Management on Profitability', European Scientific Journal, 10(1), ss. 374-381 
Akıncı, Y., G., Akıncı, M. ve Yılmaz, Ö. (2014), 'Finansal Kalkınma Sürecinin Ar-Ge Harcamaları Üzerindeki Etkisi: Schumpeter Haklı mıydı?' Maliye Dergisi, Sayı: 166, Ocak-Haziran 2014, ss.56-74

Berke, B. (2009), 'Avrupa Parasal Birliği'nde Kamu Borç Stoku ve Enflasyon İlişkisi: Panel Veri Analizi', I.Ü. İktisat Fakültesi Ekonometri ve Istatistik Dergisi, Sayı: 9, ss.30-55

Büker, S., Aşıkoğlu, R. ve Sevil, G. (2009), Finansal Yönetim, Ankara, Sözkesen Matbaacılık, ISBN: 978-46249-0-8

Ceylan, A. ve Korkmaz, T. (2008), İşletmelerde Finansal Yönetim, Bursa, Ekin Yayınevi, ISBN: 975-7338-03-6

Coşkun, E. ve Kök, D. (2011), 'Çalışma Sermayesi Politikalarının Karlılık Üzerine Etkisi: Dinamik Panel Uygulaması’, Ege Akademik Bakış, Cilt:11, Özel Sayı, ss. 75-85

Çakır H. M. ve Küçükkaplan, İ. (2012), 'İşletme Sermayesi Unsurlarının Firma Değeri ve Karlılığı Üzerindeki Etkisinin IMKB'de İşlem Gören Üretim Firmalarında 20002009 Dönemi İçin Analizi', Muhasebe ve Finansman Dergisi,(53), ss. 69-85

Deloof, M. (2003), 'Does Working Capital Management Affect Profitability of Belgian Firms?', Journal of Business Finance and Accounting, Issue 12, ss.573-587

Ecer F. ve Günay F. (2014), 'Borsa İstanbul'da İşlem Gören Turizm Şirketlerinin Finansal Performanslarının Gri İlişkisel Analiz Yöntemiyle Ölçülmesi', Anatolia: Turizm Araştırmaları Dergisi, 25(1), ss.35-48

Forghani, M., Shirazipour, M. ve Hosseini, A. (2013), 'Impact of Working Capital Management on Firms Performance', J. Basic and Applied Scientific Research, 3(7), ss.943-947

Göçer, İ.(2013), 'Teknolojik İlerlemenin Belirleyicileri: NIC Ülkeleri için Panel Eşbütünleşme ve Panel Nedensellik Analizleri', Maliye Finans Yazıları, Sayı:10, Yll:27, ss.116-141

Helhel, Y. (2016), 'The Effect of Financial Development on R\&D Activities in E7 Countries', Journal Business Research-Turk, 8(1), ss.500-517, DOI: 10.20491/isader.2016.157.

Hsiao, C., Hammond, P. ve Holly, A.(2002), Analysis of Panel Data, Cambridge University Press.

Karabay, G.(2013), 'Working Capital Management in Turkish Clothing Industry', Tekstil ve Konfeksiyon, 23(2), ss.168-175

Karadeniz E. ve İskenderoğlu Ö. (2011), 'İstanbul Menkul Kıymetler Borsası'nda İşlem Gören Turizm İşletmelerinin Aktif Karılığını Etkileyen Değişkenlerin Analizi', Anatolia: Turizm Araştırmaları Dergisi, 22(1), ss.65-75.

Karadeniz E. ve Kahiloğulları S. (2013), 'Beş Yıldızlı Otel İşletmelerinde Finansal Oranların Kullanımı: Akdeniz Bölgesi'nde Bir Araştırma', Seyahat Ve Otel İşletmeciliği Dergisi, 10(3), ss.84-106

Keskin, R. ve Gökalp, F. (2016), 'Çalışma Sermayesi Yönetiminin Firma Karlıığı Üzerine Etkisi: Panel Veri Analizi', Doğuş Üniversitesi Dergisi, 17 (1), ss.15-25

Kıran, B. (2007), 'Türkiye'de Reel Döviz Kuru ile Kısa ve Uzun Vadeli Sermaye Hareketleri İlişkisi', Marmara Üniversitesi IïBF Dergisi, Cilt: XXII, Sayı 1, ss 269283.

Öz, Y.ve Güngör, B. (2007), 'Çalışma Sermayesi Yönetiminin Firma Karlıı̆ı̆ı Üzerine Etkisi: İmalat Sektörüne Yönelik Panel Veri Analizi', Atatürk Üniversitesi, Sosyal Bilimler Enstitüsü Dergisi, 10 (2), ss.319-332.

Özçelik H. ve Kandemir B. (2015), 'BIST'de İşlem Gören Turizm İşletmelerinin Topsis Yöntemi ile Finansal Performanslarının Değerlendirilmesi', Balıkesir University Journal of Social Sciences Institute, 18(33), ss.97-114. 
Pazarlıoğlu, V. ve Gürler, K., Ö. (2007), 'Telekomünikasyon Yatırımları ve Ekonomik Büyüme: Panel Veri Yaklaşımı', Finans Politik ve Ekonomik Yorumlar, 44 (508), ss. $35-43$

Sağlam, M. ve Karaca, S., S. (2015), 'Çalışma Sermayesi Unsurlarının Firma Karlıığına Etkisi: Borsa İstanbul Şirketleri Üzerine Bir Uygulama', Gaziosmanpaşa Üniversitesi Sosyal Bilimler Araştırmaları Dergisi, 10(1), ss.100120

Saldanlı, A.(2012), 'Likidite ve Karlılık Arasındaki İlişki - IMKB 100 İmalat Sektörü Üzerine Ampirik Bir Çalışma', Süleyman Demirel Üniversitesi Sosyal Bilimler Enstitüsü, 2(16), ss.167-176

Saygılı, Ş., Cihan, C. ve Yavan, Z.A.(2006), 'Eğitim ve Sürdürülebilir Büyüme Türkiye Deneyimi, Riskler ve Fırsatlar', TÜSIAD Büyüme Stratejileri Dizisi, No:7, Yayın No: TÜSIAD-t/2006-06-420, İstanbul.

Sayılgan, G. (2010), Işletme Finansmanı, Turhan Kitabevi, Ankara, ISBN: 975-648650-3

Şahin, O. (2011), ‘'MKB’ye Kayıtı İmalat Şirketlerinde Çalışma Sermayesi Politikaları ve Firma Performansı İlişkileri', Eskişehir Osmangazi Üniversitesi IiBF Dergisi, 6 (2), ss.123-141.

Toraman, C. ve Sönmez, A., R. (2015), 'Çalışma Sermayesi ve Karlılık Arasındaki İlişki: Perakende Ticaret Sektörü Üzerine Bir Uygulama', Erzincan Üniversitesi Sosyal Bilimler Enstitüsü Dergisi (ERZSOSDE), VIII-I, ss.15-24

Wang, Y.J. (2002), 'Liquidity Management, Operating Performance, and Corporate Value: Evidence from Japan and Taiwan', Journal of Multinational Financial Management, 12(2), ss.159-169

Yardımcıoğlu, F. ve Gülmez, A (2013), 'Türk Cumhuriyetlerinde İhracat ve Ekonomik Büyüme İlişkisi: Panel Eşbütünleşme ve Panel Nedensellik Analizi', Bilgi Ekonomisi ve Yönetimi Dergisi, VIII(I), ss.145-161. 